\title{
Revelations of fundamental science
}

\section{Robert P. Crease wonders at a physics history with more than a hint of the biblical.}

$\mathrm{F}$ orget the Odyssey, the Aeneid and the Bible - the story of modern fundamental physics, Lawrence Krauss argues, is greater than all of these. What could live up to such a billing?

The tale has been told before, in outline and detail. Krauss's retelling is fast (four centuries in 300 pages) and aimed at nonscientists. Its best parts are its explanations of difficult concepts. Its worst are where Krauss, a theoretical physicist, apparently feels competitive with the Bible and the humanities.

With considerable chutzpah, Krauss breaks his book into 'Genesis, 'Exodus' and 'Revelation. 'Genesis' opens with Isaac Newton, who used geometry and calculus to understand nature. By the end of the nineteenth century, the tribe of scientists - now including Thomas Young, Michael Faraday and James Clerk Maxwell — had gained key tools with the discovery of light interference, fields and electromagnetic waves.

Krauss's accounts of early scientific struggles are certainly easy to follow. "The Church was the National Science Foundation of the fifteenth, sixteenth, and seventeenth centuries," he remarks. Of Faraday's discovery that magnets produce electricity, he writes: "Voilà, Niagara Falls, hydroelectricity, and the modern world!" Twentieth-century developments are more difficult, but Krauss provides catchy anecdotes. He explains relativity by referring to a time when he was struck by his child's projectile vomit in the car, and the different trajectories the vomit took as perceived by himself and someone outside the vehicle.

'Genesis' ends in the mid-1930s, with the discovery of the neutrino and short-range weak force. It is silly for Krauss to analogize this period to the part of the Bible in which the Jews are enslaved in Egypt, but that's the flavour of this book. Many physicists see the 1950s to 1970 s as a golden age, with soaring budgets and huge machines unearthing hordes of particles. Their prestige was at a peak. New heroes, including

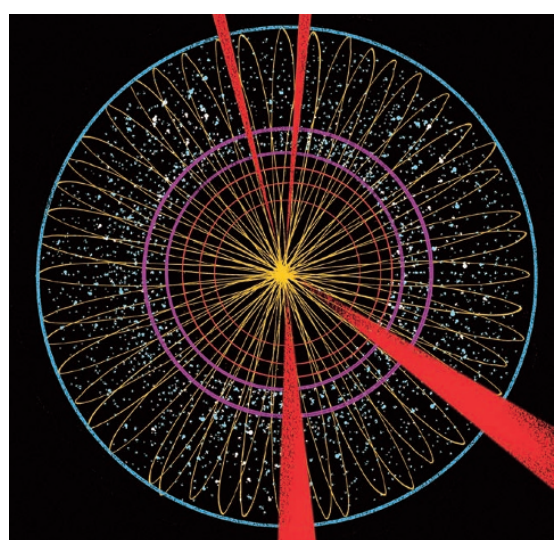

Murray Gell-Mann and Yoichiro Nambu, led further discoveries: Yang-Mills theory, parity violation, BoseEinstein condensates, quarks and the Higgs particle.

'Revelation' comes with the development in the 1970s of the standard model of particle physics, which describes all known

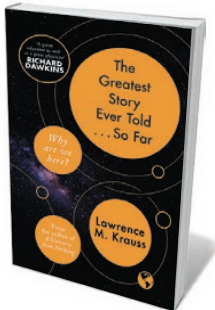

The Greatest Story Ever Told ... So Far LAWRENCE M. KRAUSS Simon \& Schuster: 2017. particles and three of the four known forces. Krauss dubs it "perhaps the greatest theoretical edifice yet created by human minds". He calls what came next the attaining of the "Promised Land" (mixing the biblical structure). Krauss also likens the discovery of the model to the allegory of the cave in Plato's Republic, in which humans are captivated by shadows and illusions, but philosophers can become aware of the 'forms' underlying existence. For Krauss, it is scientists who go "outside our cave of shadows to glimpse the otherwise hidden reality beneath the surface".

Krauss clearly covets the cachet of the humanities. He likens Albert Einstein's creativity to Vincent van Gogh's, and compares particle accelerators to Gothic cathedrals. He says his story "contains every bit as much drama, human tragedy, and exaltation" as the Aeneid, and is motivated, like that work, to parse humanity's origins and nature. These are sloppy analogies. Although we've achieved 'Revelation', for instance, Krauss says that what we now know may be almost "ephemeral" because future experimental results may change everything. The reader may be reminded less of the Aeneid than of the myth of Sisyphus, whose story never ends.

In Krauss's oversimplified take, there are two answers to the question, 'why are we here?'. The biblical one is to say that humans have a special status and that the Universe was made just for us. The other is to realize that the laws of nature are independent of us and that we are "the result of an accident in the history of the universe". He opts for the latter.

And in his invocations of the cave analogy, he omits two key features. One is that, for Plato, the forms outside the cave are unchanging, like laws of logic that cannot be disproved and are at work in all human activity, including science. Science is therefore an inner-cave activity, and those who claim it uncovers ultimate reality are priest-like pretenders. Second, the Republic is not about matter, but about justice and the Good. The central cave image helps to show what motivates the person who sees the forms to return to the cave and try to reorganize communal life, despite its difficulties. Krauss's protagonists seek only the structure of matter, and their moral message to the cave-dwellers is: "We're accidents!"

Krauss clearly thinks that his story deserves to displace the classics of the humanities. His book reveals why it can't.

Robert P. Crease is a professor in the philosophy department at Stony Brook University, New York, and co-editor-in-chief of Physics in Perspective.

e-mail:robert.crease@stonybrook.edu

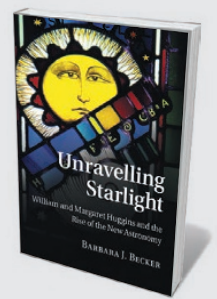

Unravelling Starlight

Barbara J. Becker (Cambridge Univ. Press, 2017) In this exhaustive biography, Barbara Becker celebrates British astronomers William and Margaret Huggins. William contributed to the origins of astrophysics as the first to use a spectroscope to detect stellar motion in the line of sight; Margaret pioneered astrophotography.

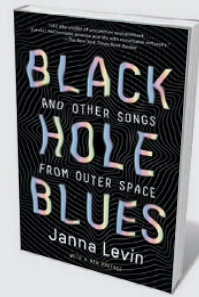

Black Hole Blues

Janna Levin (Alfred Knopf, 2017)

Astrophysicist Janna Levin records the long, arduous journey of the scientists building the nascent field of gravitational waves, from the enthusiasm of its founders to first detection five decades later (see Sheila Rowan's review: Nature 532, 28-29; 2016). Rosalind Metcalfe 